\title{
COVID-19 in-hospital Mortality: A Concise Worldwide Review
}

\section{Paul E. Marik, MD, FCCM, FCCP ${ }^{1, *}$, Jose Iglesias, DO ${ }^{2}$, Joseph Varon, MD, FCCM, FCCP ${ }^{3}$, Pierre Kory, MD ${ }^{4}$}

${ }^{1}$ Division of Pulmonary and Critical Care Medicine, Eastern Virginia Medical School, Norfolk, VA, USA

${ }^{2}$ Department of Nephrology, Hackensack Meridian School of Medicine at Seton Hall University, Nutley, NJ, USA

${ }^{3}$ Department of Critical Care Medicine, United Memorial, Medical Center, Houston, TX, USA

${ }^{4}$ Front Line Covid-19 Critical Care Alliance

*Corresponding Author: Paul E. Marik, MD, FCCM, FCCP, Professor of Medicine, Chief, Pulmonary and Critical Care Medicine, Eastern Virginia Medical School, 825 Fairfax Ave, Suite 410, Norfolk, VA 23507, USA

Received date: 16 June 2021; Accepted date: 24 June 2021; Published date: 28 June 2021

Citation: Marik PE, Iglesias J, Varon J, Kory P. COVID-19 in-hospital Mortality: A Concise Worldwide Review. J Comm Med and Pub Health Rep 2(4): https://doi.org/10.38207/jcmphr20210073

Copyright: @ 2021 Paul E. Marik. This is an open-access article distributed under the terms of the Creative Commons Attribution License, which permits unrestricted use, distribution, and reproduction in any medium, provided the original author and source are credited.

\begin{abstract}
:
Background: The global burden of death due to Coronavirus-19 (COVID-19) is considerable. The average mortality for patients hospitalized with COVID-19 has not been reported. This data is important to serve as a benchmark to compare the outcomes of studies across the globe.

Methods: We performed a scoping review of studies across the globe that reported 28-day/hospital mortality. We include studies that enrolled consecutive, unselective patients with COVID-19 and excluded studies with less than 200 participants. Studies were grouped by geographic location, namely Asia, Europe, the USA, and South America. The primary endpoint was the 28-day/ hospital mortality. Comparison across geographic areas and pairwise analysis between groups were performed employing Kruskal-Wallis one-way analysis of variance.

Results: Fifty-three studies met our inclusion criteria, enrolling a total of 767761 patients. There were 12 studies from Asia with a median mortality of $13 \%, 21$ studies from Europe with a median mortality of $23 \%, 18$ studies from the USA with a median mortality of $20 \%$, and 2 studies from South America with a median mortality of $30.0 \%$. The overall median hospital mortality of all 53 studies was $21 \%$. The mortality differed significantly between regions $(\mathrm{p}<0.001$ ). Twenty-four studies reported the percentage of patients remaining in the hospital after 28 days; this averaged $18.5 \pm 17.3$ percent. The median age was 64 years (IQR 61, 67), with age differing significantly between regions ( $<$ < 0.001). There was a good correlation between the mean age of the subjects in each study and the hospital mortality (correlation coefficient $0.575, \mathrm{p}=0.000$ ). Overall, $57 \%$ of patients were male and $21 \%$ of patients were admitted to the ICU.
\end{abstract}

Conclusion: The median hospital mortality was $21 \%$ and this varied significantly across geographic regions. Due to the large percentage of patients still hospitalized at day 28, the real hospital mortality from COVID-19 is likely much higher, reflecting the high death toll of this disease. Coronavirus-19 disease (COVID-19) emerged from China toward the end of 2019 spreading rapidly to reach every nation across the globe. Approximately $20 \%$ of patients infected with SARS-CoV-2 require hospitalization with the disease-carrying a high hospital mortality. $[1,2]$ The average mortality burden of hospitalized patients with COVID-19 has not been reported, nor has the variation across geographic areas been studied. This data is important in order to benchmark the outcomes of studies evaluating the hospital mortality of patients with COVID-19 as well as to understand geographic variations in reported hospital mortality.

Keywords: COVID-19; in-hospital mortality, review, age, world.

\section{Introduction}

Coronavirus-19 disease (COVID-19) emerged from China toward the end of 2019 spreading rapidly to reach every nation across the globe. Approximately $20 \%$ of patients infected with SARS-CoV-2 require hospitalization with the disease carrying a high hospital mortality. $[1,2]$

The average mortality burden of hospitalized patients with COVID19 has not been reported, nor has the variation across geographic areas been studied. This data is important in order to benchmark the outcomes of studies evaluating the hospital mortality of patients with COVID-19 as well as to understand geographic variations in reported hospital mortality. 


\section{Methods}

We performed a comprehensive search of PubMed, Scopus, and Google Scholar for studies published between December 1, 2019, and December 1, 2020, reported in-hospital mortality for patients admitted to hospital with coronavirus-19 (COVID-19) disease. The following keywords were used for the search: "Coronavirus 2019", "COVID-19", "SARSCoV2", "hospital mortality", "in-hospital mortality", "mortality" and "all-cause mortality". We included only those studies that enrolled consecutive, non-selective patients admitted to the hospital with COVID-19 that reported 28-day or hospital mortality. We excluded studies that enrolled less than 200 patients and those limited to critically ill patients or any other specific demographic group. The studies were screened to avoid an overlap in patient populations. The following variables were recorded for each study; first author, country, sample size, number of hospitals providing data, date of the first day of enrollment, date of last day of enrollment, mean age, percentage of male patients, percentage of patients admitted to ICU, 28-day/hospital mortality, and percentage of patients still hospitalized at day 28 . The countries were grouped as

\section{Results}

After screening 1087 published reports, 53 studies from 11 countries met our inclusion criteria. [3-55] [3-52] [53-55] The studies listed by date of enrollment are provided in Table 1. Overall, 676761 patients were enrolled in these studies. A large national database from Brazil contributed $38 \%$ of patients (254 288 patients).[17] The hospital mortality and characteristics of the studies grouped by geographic region are provided in Table 2 . While the hospital mortality varied from $3.1 \%$ (China) to $43 \%$ (Italy), the median mortality was $13 \%$ for Asia, $23 \%$ for Europe, $20 \%$ for the USA, and $30 \%$ for South America. The overall median hospital mortality of all 53 studies were $21 \%$. Twenty-four studies reported the percentage of patients remaining in the hospital after 28 days; this averaged $18 \%$. The median age was 64 years (IQR 61, 67). Overall, $57 \%$ of patients were male and $21 \%$ of patients were admitted to the ICU. There was a statistically significant difference across geographic groups in 28-day follows: Asia (including India and Iran), Europe, United States of America (USA) and South America.

The primary goal of the study was to compare the 28-day mortality across the four geographic areas; we calculated the median (IQR) 28day/hospital mortality for each geographic group and for all studies combined. Further, we explored the differences among geographic groups in age, sex, percent of patients in the ICU, percent patients requiring mechanical ventilation (MV), percent of patients in the ICU, percent mortality on MV, percent ICU mortality, and percent of patients remaining in the hospital after 28 days. As most of the variables were not normally distributed, they are reported as the median and inter-quartile range (IQR). Comparison across geographic areas and pairwise analysis between groups were performed employing Kruskal-Wallis one-way analysis of variance. Pearson's Bivariate analysis was employed to ascertain the possible relationship between 28-day mortality and age, male sex, percent of patients in the ICU, percent patients requiring mechanical ventilation (MV). Statistical analysis was performed using NCSS 2021 (Kaysville, Utah).

mortality, median age, gender, percentage of patients in the ICU, and percentage of patients receiving mechanical ventilation (Table 2). Pairwise analysis of geographic areas demonstrated significant differences in 28-day mortality differing between USA-Europe, USA-Asia, Europe-Asia, and Asia-South America (Table 2). Similarly, the pairwise analysis demonstrated significant differences in age between USA-Europe, USA-Asia, Europe-Asia, and EuropeSouth America. The utilization of ICU resources and the use of mechanical ventilation differed among geographic areas. Particularly striking is the difference in the use of MV between the USA and Asia. There was a good correlation between the mean age of the subjects in each study and the hospital mortality (correlation coefficient $0.575, \mathrm{p}$ $=0.000$; see Figure 1). The percentage of males in each study correlated poorly with hospital mortality $(r=0.25, \mathrm{p}=0.06)$.

Table 1. The studies listed by date of enrollment are:

\begin{tabular}{llllllllll}
\hline Author & Country & $\mathrm{n}$ & n-hospitals & Date started & Duration Days & Age (yrs.) & Male (\%) & ICU (\%) Mortality (\%) \\
\hline Guan [3] & China & 1590 & 575 & $12 / 11 / 2019$ & 51 & 48.0 & 57.2 & 6.2 & 3.1 \\
Wu [4] & China & 201 & 1 & $12 / 25 / 2019$ & 32 & 51.0 & 63 & 26.4 & 21.9 \\
Zhang [5] & China & 663 & 1 & $1 / 1 / 2020$ & 36 & 55.0 & 48.0 & - & 3.8 \\
Liu [6] & China & 245 & 1 & $1 / 1 / 2020$ & 59 & 53.9 & 46.5 & - & 13.8 \\
Liu [7] & China & 383 & 1 & $1 / 2 / 2020$ & 59 & 46.0 & 42.3 & - & 12.9 \\
Luo [8] & China & 1018 & 2 & $1 / 9 / 2020$ & 82 & 61.0 & 51.2 & 17.0 & 19.7 \\
Shi [9] & China & 416 & 1 & $1 / 20 / 2020$ & 21 & 64.0 & 49.3 & - & 13.7 \\
Li [10] & China & 548 & 1 & $1 / 26 / 2020$ & 10 & 60.0 & 31.0 & - & 16.5
\end{tabular}




\begin{tabular}{|c|c|c|c|c|c|c|c|c|c|}
\hline Cheng [11] & & 701 & 4 & $1 / 28 / 2020$ & 14 & 63.0 & 52.0 & 10.4 & 16.1 \\
\hline Sbidian [12] & nce & 4642 & 39 & $2 / 1 / 2020$ & 65 & 66.1 & 59.0 & 2.6 & 22.5 \\
\hline Knight [13] & UK & 35463 & 260 & $2 / 6 / 2020$ & 104 & 73.0 & 58.3 & - & 32.2 \\
\hline Docherty [14] & UK & 20133 & 208 & $2 / 6 / 2020$ & 73 & 73.0 & 59.9 & 17.0 & 26.0 \\
\hline Lodigiani [15] & Italy & 388 & 1 & $2 / 13 / 2020$ & 57 & 66.0 & 68.0 & 16.0 & 26.0 \\
\hline Fried [16] & USA & 11721 & 208 & $2 / 15 / 2020$ & 65 & 63.8 & 53.0 & 20.0 & 21.4 \\
\hline Ranzani [17] & Brazil & 254288 & - & $2 / 16 / 2020$ & 181 & 60.0 & 56.0 & 39.0 & 38.0 \\
\hline Nikpouraghdam [18] & Iran & 2968 & 1 & $2 / 19 / 2020$ & 56 & 55.0 & 66.0 & - & 8.0 \\
\hline Castelnuovo [19] & Italy & 3894 & 30 & $2 / 19 / 2020$ & 94 & 67.0 & 61.7 & - & 18.2 \\
\hline Yehia [20] & USA & 7139 & 92 & $2 / 19 / 2020$ & 102 & 68.0 & 51.3 & 40.0 & 20.3 \\
\hline Jalili [21] & Iran & 28981 & 1034 & $2 / 20 / 2020$ & 60 & 57.3 & 56.0 & - & 24.4 \\
\hline Fumagalli [22] & Italy & 516 & 2 & $2 / 22 / 2020$ & 48 & 67.0 & 66.9 & - & 23.2 \\
\hline Ciceri [23] & Italy & 950 & 1 & $2 / 25 / 2020$ & 78 & 65.0 & 68.0 & 14.0 & 17.0 \\
\hline Vena [24] & Italy & 317 & 1 & $2 / 25 / 2020$ & 29 & 71.0 & 67.0 & 20.5 & 43.0 \\
\hline Karagiannidis [25] & Germany & 10021 & 920 & $2 / 26 / 2020$ & 53 & 68.3 & 51.9 & - & 22.2 \\
\hline Navaratnam [26] & UK & 91541 & 500 & $3 / 1 / 2020$ & 91 & - & 55.3 & - & 30.8 \\
\hline Byttebier [27] & Belgium & 959 & 4 & $3 / 1 / 2020$ & 152 & 69.2 & 54.5 & - & 15.6 \\
\hline Ahschul [28] & USA & 2355 & 10 & $3 / 1 / 2020$ & 46 & 65.3 & 46.7 & - & 26.4 \\
\hline Bahl [29] & USA & 1461 & 8 & $3 / 1 / 2020$ & 30 & 62.0 & 53.0 & - & 22.3 \\
\hline Redd [30] & USA & 202 & 9 & $3 / 1 / 2020$ & 32 & 63.0 & 55.0 & 17.5 & 15.8 \\
\hline Richardson [31] & USA & 5700 & 12 & $3 / 1 / 2020$ & 31 & 63.0 & 60.3 & 14.2 & 21.0 \\
\hline Myers [32] & USA & 377 & 21 & $3 / 1 / 2020$ & 30 & 61.0 & 56.0 & 29.9 & 15.6 \\
\hline Petrilli [33] & USA & 1999 & 4 & $3 / 1 / 2020$ & 32 & 62.0 & 62.0 & 32.5 & 14.1 \\
\hline Kim [34] & USA & 2491 & 154 & $3 / 1 / 2020$ & 62 & 62.0 & 53.0 & 32.0 & 17.0 \\
\hline Nadkarni [35] & USA & 4389 & 9 & $3 / 1 / 2020$ & 60 & 65.0 & 56.0 & - & 24.0 \\
\hline Piroth [36] & France & 89530 & - & $3 / 1 / 2020$ & 60 & 65.0 & 53.0 & 16.3 & 16.9 \\
\hline Marcolino [37] & Brazil & 2054 & 25 & $3 / 1 / 2020$ & 202 & 59.0 & 52.6 & 41.4 & 22.0 \\
\hline Ayerbe [38] & Spain & 2075 & 17 & $3 / 1 / 2020$ & 50 & 67.5 & 60.0 & - & 14.5 \\
\hline Goyal [39] & USA & 393 & 2 & $3 / 3 / 2020$ & 28 & 62.0 & 60.6 & - & 10.2 \\
\hline Garibaldi [40] & USA & 832 & 5 & $3 / 4 / 2020$ & 51 & 63.0 & 53.0 & - & 16.0 \\
\hline Berenguer [41] & Spain & 4035 & 127 & $3 / 6 / 2020$ & 11 & 70.0 & 61.0 & 18.5 & 28.0 \\
\hline Santus [42] & Italy & 412 & 3 & $3 / 7 / 2020$ & 61 & 66.0 & 68.0 & - & 25.5 \\
\hline Palaiodimos [43] & USA & 200 & - & $3 / 9 / 2020$ & 13 & 64.0 & 49.0 & 16.0 & 24.0 \\
\hline Guisado-Vasco [44] & Spain & 607 & 1 & $3 / 10 / 2020$ & 36 & 69.0 & 65.0 & 8.7 & 23.2 \\
\hline Arshad [45] & USA & 2541 & 6 & $3 / 10 / 2020$ & 53 & 64.0 & 51.0 & 24.2 & 18.1 \\
\hline Goodall [46] & UK & 981 & 1 & $3 / 12 / 2020$ & 34 & 69.0 & 64.0 & - & 36.0 \\
\hline Mikami [47] & USA & 3708 & 8 & $3 / 13 / 2020$ & 35 & 66.0 & 57.0 & - & 21.7 \\
\hline Catteau [48] & Belgium & 8910 & 109 & $3 / 14 / 2020$ & 48 & 71.0 & 54.5 & & 21.6 \\
\hline Rosenberg [49] & USA & 1438 & 25 & $3 / 15 / 2020$ & 40 & 63.0 & 59.7 & 22.8 & 20.3 \\
\hline Chopra [50] & USA & 1648 & 39 & $3 / 16 / 2020$ & 107 & 62.0 & 51.8 & 13.2 & 24.2 \\
\hline Horby [51] & UK & 6425 & 176 & $3 / 19 / 2020$ & 81 & 66.0 & 64.0 & - & 24.6 \\
\hline Vizcaychipi [52] & UK & 923 & 2 & $3 / 20 / 2020$ & 33 & 67.0 & 61.7 & 15.0 & 32.0 \\
\hline Sasas-Rojo [53] & Spain & 15111 & 150 & $3 / 24 / 2020$ & 98 & 69.4 & 57.2 & 8.3 & 21.0 \\
\hline Budhiraja [54] & India & 976 & 5 & $4 / 1 / 2020$ & 60 & 47.5 & 67.1 & 29.0 & 10.5 \\
\hline Rosenthal [55] & USA & 35302 & 592 & $4 / 1 / 2020$ & 60 & 63.3 & 53.4 & 19.4 & 20.3 \\
\hline
\end{tabular}


Table 2 : Entire Cohort of studies : mortality and characteristics of hospitalized patients $\S$

\begin{tabular}{|c|c|c|c|c|c|c|c|}
\hline \multirow[b]{2}{*}{$\overline{\text { Age }}$} & \multirow{2}{*}{$\begin{array}{l}\text { USA }(\mathbf{n}=\mathbf{8 7 6 6 0}) \\
63(62,64)[18]\end{array}$} & \multicolumn{2}{|c|}{$\operatorname{Europe}(n=294069)$} & $\operatorname{Asia}(n=38690)$ & \multicolumn{2}{|c|}{$\begin{array}{l}\text { South America } \\
(\text { Brazil })(n=256,312)\end{array}$} & \multirow{2}{*}{$\begin{array}{l}\mathbf{p} \\
0.00001 \mathrm{II}\end{array}$} \\
\hline & & 67 & $(66,69)[21]$ & $54 \quad(48,61)[12]$ & 59 & $(44.45)[2]$ & \\
\hline \% Male & $51(53,58)[18]$ & 61 & $(56,65)[21]$ & $48 \quad(58,51)[12]$ & 54 & $(39,53)[2]$ & 0.001 \\
\hline $\operatorname{ICU}(\%)$ & $20(16,32)[12]$ & 16 & $(14,20)[10]$ & $17 \quad(8,28)[5]$ & 40 & $(29,31)[2]$ & 0.043 II \\
\hline MV (\%) & $18(12,22)[15]$ & 15 & $(10,17)[11]$ & $8(3,13)[7]$ & 27 & $(17,24)[2]$ & 0.023 II \\
\hline $\begin{array}{l}\text { Hospital 28-day } \\
\text { mortality (\%) }\end{array}$ & $20(16,23)[18]$ & 23 & $(20,29)[21]$ & $13(9,17)[12]$ & 30 & $(16,29)[2]$ & 0.00001 II \\
\hline $\begin{array}{l}\text { Ventilator Mortality } \\
(\mathrm{MV})(\%)\end{array}$ & $46(36,71)[8]$ & 40 & $(35,59)[5]$ & $*$ & 80 & [1] & 0.46 \\
\hline ICU Mortality (\%) & $64(37,68)[2]$ & 29 & $(20,34)[2]$ & $*$ & 53 & $(35,44)[2]$ & 0.19 \\
\hline $\begin{array}{l}\% \text { Patients } \\
\text { remaining in } \\
\text { hospital }\end{array}$ & $12(6,33)[8]$ & 13 & $(9,20)[12]$ & $19 \quad(6,76)[3]$ & 24 & $(9,38)[2]$ & 0.22 \\
\hline Number of studies & 18 & 21 & & 12 & 2 & & \\
\hline
\end{tabular}

$\S$ Median (IQR) [number of studies reported] * No data reported

II Pairwise differences between groups ( $\mathrm{p}=$ less than 0.05)

Age: USA-Europe, Europe-Asia, USA-Asia, Europe-South American.

Gender: Europe-Asia; USA-Europe.

\% In ICU: Europe-South America, Asia-South America.

$\%$ on MV: USA-Asia, Europe- South America, Asia- South America.

28-day mortality: USA-Europe, USA-Asia, Europe-Asia, Asia-South America

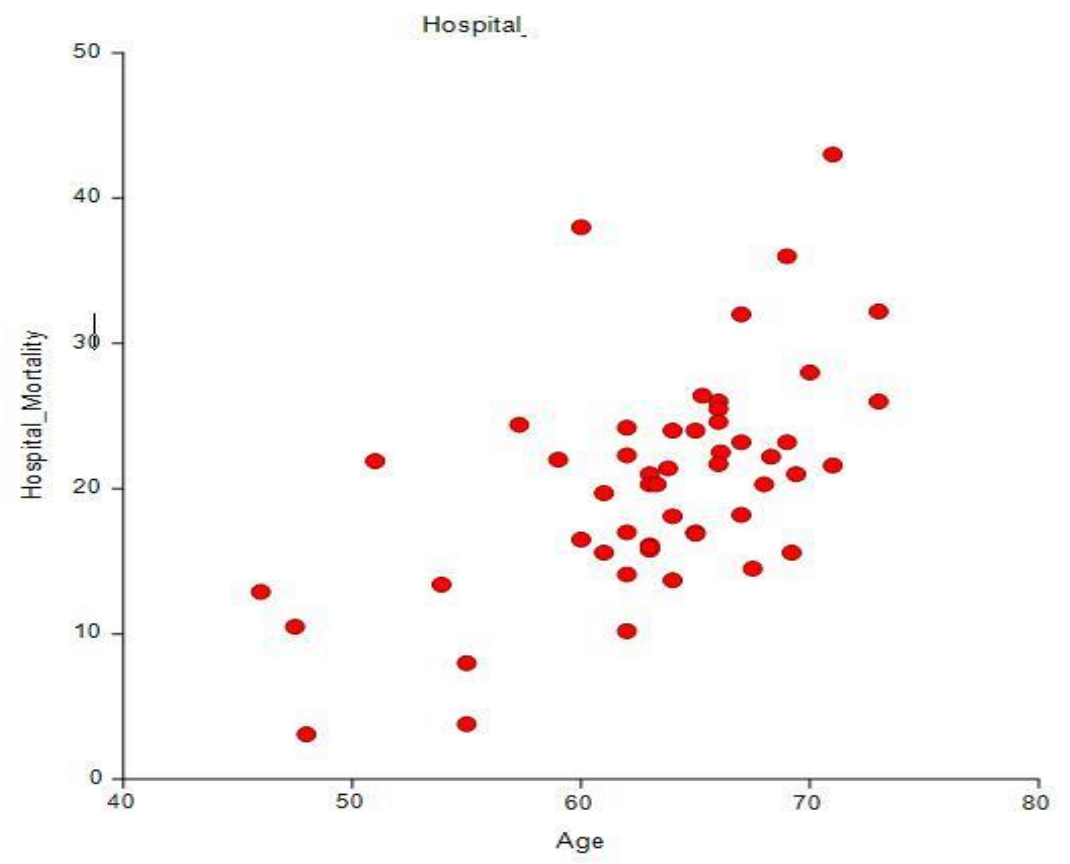

Figure 1. Plot of Age versus Hospital mortality

\section{Discussion}

The median in-hospital/28-day mortality for COVID-19 averaged 21 $\%$ across the globe. This mortality statistic is useful to compare studies that evaluate the outcomes of patients hospitalized with COVID-19. Due to the high percentage of patients remaining in hospital at day 28, the true hospital mortality is likely much higher and closer to $30 \%$. Furthermore, we noted a marked variation in mortality between geographic regions across the globe. Strikingly, the average mortality was low in China (13\%) while it was high in South America-Brazil $(30 \%)$. The low mortality reported in the Chinese studies is likely related to the low median age of the patients (54 years; IQR 48-61) as well as hospital admission criteria (and hospital resources) which likely differed from other parts of the world. As has been demonstrated in previous studies, age is a major determinant of outcome 
in patients hospitalized with COVID-19. [56-58] Although the incidence of comorbidities increases with aging, this alone does not completely explain the effect of age on mortality. A large meta-analysis that evaluated comorbidities and disease severity across geographic areas demonstrated that the proportion of the three major comorbidities diabetes mellitus, hypertension, and cardiovascular disease was highest in the USA compared to Europe and Asia, with Asia demonstrating the lowest proportional burden of comorbidities.[59] Despite this Asia was noted to have a higher degree of severity

of illness when compared with the burden of comorbidities. $[\mathbf{5 9 , 6 0 ]}$ One of the potential mechanisms to explain the increased mortality with aging is phenomenon is immunosenescence, whereby a failure to mount an effective adaptive immune response leads to the

\section{Conclusions}

The median hospital mortality for COVID-19 averaged $21 \%$, however, this statistic varied widely by geographic area, being lowest in Asia and highest in South America. Furthermore, while patient's age and

\section{Declarations}

Ethics approval: Not relevant

Availability of data: Available on request

\section{References}

1. Wu Z, McGoogan JM (2020) Characteristics of and important lessons from the Coronavirus Disease 2019 (COVID-19) outbreak in China. Summary of a report of 72314 cases from the Chinese Center for Disease Control and Prevention. JAMA. 323(13): $1239-1242$.

2. Li J, Huang DQ, Zou B, Yang H, Hui WZ, et al. (2021) Epidemiology of COVID-19: A systematic review and metaanalysis of clinical characteristics, risk factors and outcomes. J Med Virol. 93(3): 1449-1458.

3. Guan WJ, Liang WH, Zhao Y, Liang HR, Chen ZS, et al. (2020) Comorbidity and its impact on 1590 patients with COVID-19 in China: a nationwide analysis. Eur Resp J. 55(5): 2000547.

4. Wu C, Chen X, Cai Y, Xia J, Zhou X, et al. (2020) Risk factors associated with acute respiratory distress syndrome and death in patients with Coronavirus disease 2019 pneumonia in Wuhan,China. JAMA Intern Med. 180(7): 934-943.

5. Zhang J, Wang X, Jia X, Li J, Hu K, et al. (2020) Risk factors for disease severity, unimprovement, and mortality in COVID-19 patients in Wuhan,China. Clin Microbiol Infect. 26(6): 767-722.

6. Liu Y, Du X, Chen J, Jin Y, Peng L, et al. (2020) Neutrophil-tolymphocyte ratio as an independent risk factor for mortality in hospitalized patients with COVID-19. J Infection. 81(1): e6-e12.

7. Liu Y, Sun W, Guo Y, Chen L, Zhang L, et al. (2020) Association between platelet parameters and mortality in coronavirus disease 2019: Retrospective cohort study. Platelets. 31(4): 490-496. dysregulated release of cytokines. In addition, inflammation, a chronic low-grade inflammation that develops with advanced age may contribute to immune dysregulation and poorer outcome in elderly patients.[58] In the current study, it is noteworthy that the use of MV differed significantly between the USA and Asia. Multiple potential factors may account for this observation including the effect of age, more liberal admission criteria with lower severity of illness, and different approaches to the management of COVID-19 patients. The mortality of $38 \%$ reported in the large national Brazilian study is noteworthy.[17] This is likely due to the large disease burden in this lower-middle-income country with regional disparities in the provision and accessibility of health care.

comorbidities as well as admission criteria influence hospital mortality, the accessibility of health care and availability of medical resources likely have a major impact on patient outcomes.

Competing interests: None of the authors has any competing interests in the manuscript.

Funding: This study was unfunded.

8. Luo M, Liu J, Jiang W, Yue S, Liu H, et al. (2020) Il-6 and CD8+ $\mathrm{T}$ cell counts combined are an early predictor of in-hospital mortality of patients with COVID-19. JCI Insight. 5(13): e139024.

9. Shi S, Qin M, Shen B, Cai Y, Liu T, et al. (2020) Association of cardiac injury with mortality in hospitalized patients with COVID-19 in wuhan,China. JAMA Cardiol. 5(7): 802-810.

10. Li X, Xu S, Yu M, Wang K, Tao Y, et al. (2020) Risk factors for severity and mortality in adult COVID-19 inpatients in Wuhan. $\mathrm{J}$ Allergy Clin Immunol. 146(1): 110-118

11. Cheng Y, Luo R, Wang K, Zhang M, Wang Z, et al. (2020) Kidney disease is associated with in-hospital death of patients with COVID-19. Kidney Int. 97(5): 829-838.

12. Sbidian E, Josse J, Lemaitre G, Meyer I, Bernaux M, et al. (2020) Hydroxychloroquine with or without azithromycin and inhospital mortality or discharge in patients hospitalized for COVID-19 infection: a cohort study of 4,642 in-patients in France. medrx.

13. Knight SR, Ho A, Pius R, Buchan I, Carson G, et al. (2020) Risk stratification of patients admitted to hospital with Covid-19 using the ISARIC WHO clinical characterisation protocol: development and validation of the 4C Mortality Score. BMJ. 370: m3339.

14. Docherty AB, Harrison EM, Green CA, Hardwick HE, Pius R, et al. (2020) Features of 20133 UK patients in hospital with covid- 
19 using the ISARIC WHO Clinical Characterisation protocl: prospective observational cohort study. BMJ. 369: m1985.

15. Lodigiani C, Iapichino G, Carenzo L, Cecconi M, Ferrazzi P, et al. (2020) Venous and arterial thromboembolic complications in COVID-19 patients admitted to an academic hospital in Milan, Italy. Thrombosis Research. 191: 9-14.

16. Fried MW, Crawford JM, Mospan AR, Watkins SE, Munoz B, et al. (2020) Patient characteristics and outcomes of 11,721 patients with COVID-19 hospitalized across the United States. Clin Infect Dis. 72(10): e558-e565.

17. Ranzani OT, Bastos LS, Gelli JB, Marchesi JF, Baião F, et al. (2021) Characterisation of the first 250000 hospital admissions for COVID-19 in Brazil: a retrospective analysis of nationwide data. Lancet Resp Med. 9(4): 407-418.

18. Nikpouraghdam M, Farahani AJ, Alishiri GH, Heydari S, Ebrahimnia M, et al. (2020) Epidemiological characteristics of coronavirus disease 2019 (COVID-19) patients in IRAN: A single center study. J Clin Virol. 127: 104378.

19. Di Castelnuovo A, Bonaccio M, Costanzo S, Gialluisi A, Antinori A, et al. (2020) Common cardiovascular risk factors and inhospital mortality in 3,894 patients with COVID-19: survival analysis and machine learning-based findings from the multicentre Italian CORIST study. Nutr Metab Cardiovasc Dis. 30(11): 1899-1913.

20. Yehia BR, winegar A, Fogel R, Fakih M, Ottenbacher A, et al (2020) Association of race with mortality among patient hospitalized with Coronavirus Disease 2019 (COVID-19) at 92 US hospitals. JAMA Network Open. 3(8): e2018039.

21. Jalili M, Payandemehr P, saghaei A, Sari HN, Safikhani H, et al. (2021) Characteristics and mortality of hospitalized patients with COVID-19 in Iran: A national retrospective cohort study. Ann Intern Med. 174(1): 125-127.

22. Fumagalli C, Rozzini R, Vannini M, Coccia F, Cesaroni G, et al. (2020) Clinical risk score to predict in-hospital mortality in COVID-19 patients: a retrospective cohort study. BMJ Open. 10 e040729.

23. Ciceri F, Ruggeri A, Lembo R, Puglisi R, Landoni G, et al. (2020) Decreased in-hospital mortality in patients with COVID-19 pneumonia. Pathog Glob Health. 114(6): 281-282.

24. Vena A, Giacobbe DR, Di Biagio A, Mikulska M, Taramasso L, et al. (2020) Clinical characteristics, management and in-hospital mortality of patients with coronavirs disease in Genoa,Italy. Clin Microbiol Infect. 26(11): 1537-1544.

25. Karagiannidis C, Mostert C, Hentschker C, Voshaar T, Malzahn J, et al. (2020) Case characteristics, resource use, and outcomes of 10021 patients with COVID-19 admitted to 920 German hospitals: an observational study. Lancet Resp Med. 8(9): 853862.

26. Navaratnam AV, Gray WK, Day J, Wendon J, Briggs TWR (2021) Patient factors and temporal trends associated with COVID-19 in- hospital mortality in England: an observational study using administrative data. Lancet Resp Med. 9(4): 397-406.

27. Byttebier G, Belmans L, Alexander M, Saxberg BEH, Spiegeleer BD, et al. (2021) Hospital mortality in COVID-19 patients in Belgium treated with statins, ACE inhibitors and/or ARBs. medRxiv. 1-10.

28. Altschul DJ, Unda SR, Benton J, Ramos RDLG, Cezayirli P, et al. (2020) A novel severity score to predict inpatient mortality in COVID-19 patients. Scientific Reports. 10: 16726.

29. Bahl A, Van Baalen MN, Ortiz L, Chen NW, Todd C, et al. (2020) Early predictors of in-hospital mortality in patients with COVID-19 in a large American cohort. Intern Emerg Med. 1-15.

30. Redd WD, Zhou JC, Hathorn KE, McCarty TR, Bazarbashi AN, et al. (2020) Prevalence and characteristics of gastrointestinal symptoms in patients with SARS-CoV-2 infection in the United States: A multicenter cohort study. Gastroenterology. 159(2): 765-767.e2.

31. Richardson S, Hirsch JS, Narasimhan M, Crawford JM, McGinn T, et al. (2020) Presenting characteristics, comorbidities, and outcomes among 5700 patients hospitalized with COVID-19 in the New York City Area. JAMA. 323(20): 2052-2059.

32. Myers LC, Parodi SM, Escobar GJ, Liu VX (2020) Characteristics of hospitalized adults with COVID-19 in an integrated health care system in California. JAMA. 323(21): 2195-2198.

33. Petrilli CM, Jones SA, Yang J, Rajagopalan H, O'Donnell L, et al. (2020) Factors associated with hospitalization and critical illness among 4,103 patients with COVID-19 disease in New York City. medRxiv. 369: m1966

34. Kim L, Garg S, O'Halloran A, Whitaker M, Pham H, et al. (2020) Risk factors for intensive care unit admission and in-hospital mortality among hospitalized adults through the U.S. Coronavirus Disease 2019 (COVID-19)-Associated hospitalization surveillance network (COVID-NET). Clin Infect Dis. 72(9): e206-e214.

35. Nadkarni GN, Lala A, Bagiella E, Chang HL, Moreno PR, et al. (2020) Anticoagulation, mortality, bleeding and pathology among patients hospitalized with COVID-19: A Single Health System Study. J Am Coll Cardiol. 76(16): 1815-1826.

36. Piroth L, Cattenet J, Mariet AS, Bonniaud P, Blot M, et al. (2020) Comparison of the characteristics, morbidity, and mortality of COVID-19 and seasonal influenza: a nationwide, populationbased retrospective cohort study. Lancet Resp Med. 9(3): 251259.

37. Marcolino MS, Ziegelmann PK, Souza-Sliva MV, Nascimento IJB, Oliveira LM, et al. (2021) Clinical characteristics and outcomes of patients hospitalized with COVID-19 in Brazil: results from the Brazilian COVID-19 registry. Int J Infect Dis. 107: $300-310$

38. Ayerbe L, Risco-Risco C, Ayis S (2020) The association of treatment with hydroxychloroquine and hospital $\mathrm{m}$ ortality in 
COVID-19 patients. Internal and Emergecy Medicine. 15: 15011506.

39. Goyal P, Choi JJ, Pinheiro LC, Schenck EJ, Chen R, et al. (2020) Clinical characteristics of COVID-19 in New York City. N Engl J Med. 382(24): 2372-2374.

40. Garibaldi BT, Fiksel J, Muschelli J, Robinson ML, Rouhizadeh M, et al. (2021) Patient trajectories among persons hospitalized for COVID-19. A cohort study. Ann Intern Med. 174(1): 33-41.

41. Berenguer J, Ryan P, Rodriguez-Bano J, Jarrín I, Carratalà J, et al. (2020) Characteristics and predictors of death among 4035 consecutively hospitalized patients with COVID-19 in Spain Clinical Microbiology \& Infection. 26(11): 1525-1536.

42. Santus P, Radovanovic D, Saderi L, Marino P, Cogliati C, et al. (2020) Severity of respiratory failure at admission and in-hospital mortality in patients with COVID-19: a prospective observational multicentre study. BMJ Open. 10(10): e043651.

43. Palaiodimmos L, Kokkinidis DG, Li W, Karamanis D, Ognibene J, et al. (2020) Severe obesity, increasing age and male sex are independently associated with worse in-hospital outcomes, and higher in-hospital mortality, in a cohort of patients with COVID19 in the Bronx, New York. Metabolism. 108: 154262.

44. Guisado-Vasco P, Valderas-Ortega S, Carralon-Gonzalez MM, Roda-Santacruz A, González-Cortijo L, et al. (2020) Clinical characteristics and outcomes among hospitalized adults with severe COVID-19 admitted to a tertiary medical center and receiving antiviral, antimalarials, glucocorticoids, or immunomodulation with tocilizumab or cyclosporine: A retrospective observational study (COQUIMA cohort). EClinicalMedicine. 28: 100591.

45. Arshad S, Kilgore P, Chaudry ZS, Jacobsen G, Wang DD, et al (2020) Treatment with hydroxychloroquine, azithromycin, and combination in patients hospitalized with COVID-19. Int J Infect DIs. 97: 396-403.

46. Goodall JW, Reed TAN, Ardissino M, Bassett P, Whittington AW, et al. (2020) Risk factors for severe disease in patients admitted with COVID-19 to a hospital in London, England: a retrospective cohort study. medRxiv. 148: e251.

47. Mikami T, Miyashita H, Yamada T, Harrington M, Steinberg D, et al. (2020) Risk factors for mortality in patients with COVID-19 in New York City. J Gen Intern Med. 36(1): 17-26.

48. Catteau L, Dauby N, Montourcy M, Bottieau E, Hautekiet J, et al. (2020) Low-dose hydroxychloroquine therapy and mortality in hospitalized patients with COVID-19: a nationwide observational study of 8075 participants. International Journal of Antimicrobial Agents. 56(4): 106144.

49. Rosenberg ES, Dufort EM, Udo T, Wilberschied LA, Kumar J, et al. (2020) Association of treatment with hydroxychloroquine or azithromycin with in-hospital mortality in patients with COVID19 in New York State. JAMA. 323(24): 2493-2502.
50. Chopra V, Flanders SA, O'Malley M, Malani AN, Prescott HC (2020) Sixty-day outcomes among patients hospitalized with COVID-19. Ann Intern Med. 174(4): 576-578.

51. Horby P, Lim WS, Emberson JR, Mafham M, Bell JL, et al. (2020) Effect of Dexamethasone in hospitalized patients with COVID-19-Preliminary report. N Engl J Med.

52. Vizcaychipi MP, Shovlin CL, Hayes M, Singh S, Christie L, et al. (2020) Early detection of severe COVID-19 disease patterns define near real-time personalized care, bioseverity in males, and decelerating mortality rates. medRxiv.

53. Casas-Rojo JM, Anton-Santos JM, Milan-Nunez-Cortes J, Lumbreras-Bermejo C, Ramos-Rincón JM, et al. (2020) Clinical characteristics of patients hospitalized with COVID-19 in Spain: results from the SEMI-COVID-19 Registry. Rev Clin Esp. 220(8): 480-494.

54. Budhiraja S, Soni A, Jha V, Indrayan A, Dewan A, et al. (2020) Clinical profile of first 1000 COVID-19 cases admitted at tertiary care hospitals and the correlates of their mortality: An Indian Experience. medRxiv.

55. Rosenthal N, Cao Z, Gundrum J, Sianis J, Safo S (2020) Risk factors associated with in-hospital mortality in a US National Sample of patients with COVID-19. JAMA Network Open. 3(12): e2029058.

56. Ahmad Q, DePerrior SE, Dodani S, Edwards JF, Marik PE (2020) Role of inflammatory biomarkers in the prediction of ICU admission and mortality in patients with COVID-19. Medical Research Archives. 8(12): 1-10.

57. Zheng Z, Peng F, Xu B, Zhao J, Liu H, et al. (2020) Risk factors of critical \& mortal COVID-19 cases: A systematic literature review and meta-analysis. J Infect. 81(2): e16-e25.

58. Kang SJ, Jung SI (2020) Age-related morbidity and mortality among patients with COVID-19. Infect Chemothe. 52(2): 154164.

59. Thakur B, Dubey P, Benitez J, Torres JP, Reddy S, et al. (2021) A systematic review and meta-analysis of geographic differences in comorbidities and associated severity and mortality among individuals with COVID-19. Scientific Reports.11: 8562.

60. Fu L, Wang B, Yuan T, Chen X, Ao Y, et al. (2021) Clinical characteristics of coronavirus disease 2019 (COVID-19) in China: A systematic review and meta-analysis. J Infect. 80(6): 656-665. 